104 Literatura e Sociedade

\title{
LITERATURA E SOCIEDADE HOJE
}

\section{Edu TerukI Otsuka}

Universidade de São Paulo

Resumo

Tendo como ponto de partida o livro Literatura e sociedade (1965), este artigo procura repassar alguns aspectos da crítica de Antonio Candido, pelo ângulo da atualidade, com base em seus principais comentadores.

Abstract

This paper takes the book Literature and society (1965) as its point of departure and outlines a reassessment of some aspects of Antonio Candido's criticism from the standpoint of the present, grounded on the leading commentators of his work.
Palavras-chave

Antonio

Candido;

Literatura e

sociedade;

Experiência

brasileira

Keywords

Antonio

Candido;

Literature and

society;

Brazilian

experience 
eler Literatura e sociedade hoje talvez exija levar em consideração as linhas mestras da obra de Antonio Candido, numa visada que não se restrinja ao livro tomado isoladamente. Apresentando um cunho teórico-metodológico mais saliente, em contraste com a habitual discrição do autor nesse terreno, o livro poderia ser visto como oportunidade única para observar e discutir a teoria de Candido, buscando-a, por exemplo, no ensaio de abertura, "Crítica e sociologia" - embora talvez não seja exatamente ali que se encontrarão os resultados teóricos mais significativos de sua obra (sem que com isso se pretenda sugerir que haja insuficiência teórica no ensaio mencionado). A propósito, cabe lembrar que a Formação da literatura brasileira havia passado por tal desvio de foco na maneira como foi recebida: como se há de recordar, no prefácio à segunda edição da Formação, datado de 1962, o autor notava que apenas a "Introdução" havia sido comentada nas recensões, e o interesse desproporcional pelo método seria um sintoma de que se preferia falar sobre como fazer crítica a fazê-la efetivamente. Em outras palavras, os resultados crítico-teóricos da obra, que se encontram no corpo dos capítulos, e que se ligam à especificação do processo de adensamento da experiência cultural brasileira, não foram assimilados em todo o seu alcance naquele momento e frutificaram pouco.

No prefácio à terceira edição de Literatura e sociedade, datado de 1972, Antonio Candido explica que o livro apresenta "formulações gerais" que ele mesmo considerava etapa inicial para os ensaios analítico-interpretativos elaborados desde 1964 e publicados a partir de 1970. Como se sabe, entre esses ensaios encontram-se aqueles que hoje estão reunidos na primeira parte de O discurso e a cidade: "Dialética da malandragem" (1970), "Degradação do espaço" (1972), "O mundo-provérbio" (1972) e "De cortiço a cortiço" (redigido em 1973). E é neles

${ }^{1}$ Literatura e sociedade: estudos de teoria e história literária. 6a ed. São Paulo, Nacional, 1980. (A la ed. é de 1965.) 
que a produtividade do método se mostraria por inteiro - especialmente, para o que nos interessa destacar, nos dois estudos sobre romances brasileiros.

Em "Crítica e sociologia" encontra-se a conhecida formulação segundo a qual "o externo (no caso, o social) importa, não como causa, nem como significado, mas como elemento que desempenha um certo papel na constituição da estrutura, tornando-se, portanto, interno". O elemento social não é tomado exteriormente, como referência temática ou enquadramento contextual, mas como "fator da própria construção artística". Trata-se de efetuar uma "interpretação estética que assimilou a dimensão social como fator de arte"; ou seja, o dado social não apenas fornece matéria para a elaboração da obra, mas é elemento da estruturação da obra de arte enquanto obra de arte, sendo, por isso, indispensável a sua investigação pela crítica, na medida em que, convertido em fator interno, atua como determinante do valor estético.

Apesar de singelas, são formulações que dão maior contundência a uma perspectiva crítica que já era sinalizada na Formação, ${ }^{2}$ e que seriam posteriormente retomadas no prefácio a $O$ discurso e a cidade. Essas formulações não eram apenas proposições metodológicas; além de decorrência do indispensável trabalho analítico com obras concretas, eram também resultado da observação das insuficiências da crítica "sociológica" até aquele momento, ou seja, da reflexão sobre o fracasso da crítica em realizar a investigação dialética (dentro, é claro, dos limites do quadro considerado por Candido, que não menciona Adorno, por exemplo). Contrapondo-se simultaneamente às tendências formalistas da crítica literária (que se acentuariam logo depois) e ao marxismo mecanicista, o que o crítico apresenta é uma solução própria para o problema central da crítica literária marxista, digamos, pós-lukácsiana: a dialética de forma literária e processo social, como mostrou Roberto Schwarz ao comentar os ensaios analíticos de Candido, sobre as Memórias de um sargento de milícias e sobre $O$ cortiço, em que a dialética pode ser apreendida em ato. ${ }^{3}$

Por isso mesmo, Candido diz, no Prefácio à terceira edição de Literatura e sociedade, que seu intuito era superar os estudos de tipo "paralelístico", que consistem em apontar aspectos sociais de um lado e, de outro, correndo em paralelo, a sua ocorrência nas obras. Os estudos paralelísticos, em que geralmente redundava, então como agora, a crítica que procurou levar em consideração os

\footnotetext{
2 "Uma obra é uma realidade autônoma, cujo valor está na fórmula que obteve para plasmar elementos não-literários [...]. A sua importância quase nunca é devida à circunstância de exprimir um aspecto da realidade, social ou individual, mas à maneira por que o faz. [...] Com efeito ao contrário do que pressupõem os formalistas, a compreensão da obra não prescinde a consideração dos elementos inicialmente não-literários. O texto não os anula, ao transfigurá-los e, sendo um resultado, só pode ganhar pelo conhecimento da realidade que serviu de base à sua realidade própria. Por isso, se o entendimento dos fatores é desnecessário para a emoção estética, sem o seu estudo não há crítica". (Formação da Literatura Brasileira (momentos decisivos). 7a. ed. Belo Horizonte: Itatiaia; 1993. vol. I, p. 34.)

${ }^{3}$ Roberto Schwarz. "Pressupostos, salvo engano, de 'Dialética da malandragem”'. In: Que Horas São? São Paulo, Companhia das Letras, 1987. pp. 129-155; "Adequação nacional e originalidade crítica”. In: Seqüências brasileiras. São Paulo, Companhia das Letras, 1999, pp. 24-45.
} 
aspectos sociais na literatura, não chegam a captar uma efetiva interpenetração, de tal modo que o social permanece como dado externo. E, principalmente, tais estudos, quando muito, apenas confirmam algo que já se sabia de antemão, pois se limitam a reencontrar, nos assuntos da obra, aquilo que já tinha sido assentado no campo dos estudos sociais ou da historiografia. Em outras palavras, a crítica paralelística não chega a levar a sério o valor cognitivo da forma literária, pois não demonstra de que modo a literatura produz conhecimento nos seus próprios termos.

É justamente neste ponto que os ensaios "Dialética da malandragem" e "De cortiço a cortiço" mostram todo o alcance da crítica dialética: o teor de conhecimento das obras, que só a análise da forma pode expor à luz do dia, é imprevisível, e o êxito crítico não está assegurado de antemão, não cabendo em considerações metodológicas prévias. Assim, nos estudos analíticos, os resultados crítico-teóricos decorrem de seu empenho propriamente interpretativo, isto é, da atitude crítica que procura "explicar o aparente pelo oculto", ${ }^{5}$ o que poderia ser traduzido como a investigação dos fundamentos materiais e históricos das formas socioculturais e das formas literárias que as elaboram. Não se trata, portanto, de apenas remeter ao contexto genético da obra, mas sim de apresentar a articulação precisa entre a forma artística e a estruturação do processo social correspondente, investigando suas mediações. Dito de outro modo, essa crítica busca efetuar uma exposição de seu objeto em várias dimensões, abrangendo a reconstituição do processo, cuja força estruturadora pode ser apreendida na descoberta das formas sociais mediadoras, desentranhadas da configuração artística, sendo esta examinada em seu movimento próprio - e sem essa reconstituição, a exposição dialética ficaria incompleta. ${ }^{6}$

Assim, Candido busca estudar, não apenas a estrutura, mas também a estruturação, o processo que estrutura a estrutura, ${ }^{7}$ ou, em outros termos do crítico, a formalização estética dos materiais não-literários, processo que mais tarde ele

\footnotetext{
4 "Acho que é melhor sempre partir das formas, porque delas é possível chegar ao que literatura é como conhecimento." Antonio Candido. Entrevista (à revista Trans/form/ação). In: Brigada ligeira e outros escritos. São Paulo, Ed. Unesp, 1992. p. 242.

${ }^{5}$ Antonio Candido. Entrevista. Investigações: Lingüística e Teoria Literária, vol. 7, Recife, UFPE, setembro de 1997, p. 9.

${ }^{6}$ Nisto Antonio Candido se diferencia de Erich Auerbach, cuja monumental Mimesis é, sabidamente, muito estimada por ele (sendo mencionada com aplauso ao final de "Crítica e sociologia"). Lendo, por exemplo, o admirável capítulo "Na mansão de La Mole", no entanto, procuraremos em vão pelo fundamento histórico da inovação formal flaubertiana, a saber, a "mudança de registro" da luta de classes após os massacres de junho de 1848. Ver Paulo Arantes. O fio da meada: uma conversa e quatro entrevistas sobre Filosofia e vida nacional. Rio de Janeiro, Paz e Terra, 1996. p. 111; e "Providências de um crítico literário na periferia do capitalismo", in: Sentido da formação: três estudos sobre Antonio Candido, Gilda de Mello e Souza e Lúcio Costa. Rio de Janeiro, Paz e Terra, 1997, p. 40. Para uma aproximação entre Candido e Auerbach, ver Leopoldo Waizbort. A passagem do três ao um: Crítica Literária, Sociologia, Filologia. São Paulo, Cosac Naify, 2007.

${ }^{7}$ Cf. Antonio Candido. Entrevista (à revista Trans/form/ação). In: Brigada ligeira e outros escritos. São Paulo, Ed. Unesp, 1992. pp. 232-233. Ver também Roberto Schwarz. "Saudação honoris causa". In: Seqüencias brasileiras, pp. 12-13.
} 
denominou "redução estrutural". ${ }^{8}$ Estamos longe, portanto, da simples relação entre literatura e sociedade na acepção corriqueira, isto é, paralelística; o decisivo é antes a transformação implicada na criação literária. ${ }^{9}$ Em outras palavras, é na especificidade estética da elaboração formal que o crítico encontrará a cifra da sociedade de que a obra se apartou ao configurar-se. Na lógica própria da forma literária se adensa o conhecimento que as obras fornecem, em virtude de sua consistência interna, por vezes abrindo perspectivas inesperadas, levantando questões inoportunas, ou divergindo dos esquemas estabelecidos. ${ }^{10}$

Apenas para situar Literatura e sociedade no quadro da crítica literária brasileira do tempo, vale lembrar alguns pontos de referência, ainda que sumariamente. Como é do conhecimento geral, em 1958 Antonio Candido começou a lecionar Literatura na Faculdade de Filosofia, Ciências e Letras de Assis, no interior do estado de São Paulo (ele era, até então, assistente de Fernando de Azevedo na cadeira de Sociologia da USP), passando a trabalhar também em âmbito acadêmico com o que era seu principal objeto na crítica de rodapé. ${ }^{11}$ Em 1960, deu um curso sobre o romance romântico brasileiro, concentrando-se em Senhora, de Alencar, e em Memórias de um sargento de milícias, de Manuel Antônio de Almeida. ${ }^{12}$ Não por acaso, é uma breve análise do romance de Alencar que servirá de ponto de partida para as considerações metodológicas de "Crítica e sociologia"; além disso, ao que tudo indica, naquele momento Candido já desenvolvia a análise que daria base para a redação de "Dialética da malandragem".

Em 1961, ano em que se criaria na USP o curso de Teoria Literária e Literatura Comparada (inicialmente chamado de Teoria da Literatura), realizou-se na

${ }^{8}$ A expressão aparece, possivelmente pela primeira vez, em "Dialética da malandragem" ( $O$ discurso e a cidade. São Paulo, Duas Cidades, 1993. p. 33), sendo retomada no Prefácio a O discurso e a cidade, p. 9. Talvez seja o caso de deixar indicado que não se trata de algo exclusivo à forma romance: leia-se a análise do filme Os deuses malditos, de Visconti, escrita em colaboração com Gilda de Mello e Souza, em que, aliás, a expressão comparece: "Os deuses malditos" (1971), in: Gilda de Melo Souza. Exercícios de leitura. São Paulo, Duas Cidades, 1980. pp. 169-180. Veja-se ainda como ele introduz um de seus artigos sobre poesia, valendo-se de termos assemelhados aos que usa para explicar a redução estrutural: "O mundo desfeito e refeito" (1992). In: Recortes. São Paulo, Companhia das Letras, 1993. p. 30. Com diferentes graus de "deformação" pela fantasia, a elaboração literária nunca é para Candido mera transposição do real (como se tal coisa fosse possível), pois toda mimese já é uma poiese, como ele lembra em "Crítica e sociologia".

9 "O que me interessa não é tanto a relação do texto com a sociedade, é a transformação da sociedade em texto, devida ao processo de 'redução estrutural'." Antonio Candido. Entrevista 30/09/1996. In: Luiz Carlos Jackson. A tradição esquecida: Os parceiros do rio Bonito e a Sociologia de Antonio Candido. Belo Horizonte, Ed. UFMG, 2002. p. 170.

${ }^{10}$ Cf. Roberto Schwarz. "Pressupostos...", p. 147.

${ }^{11}$ Após a fase inicial na revista Clima (1941-1944), Antonio Candido foi "crítico titular" da Folha da Manhã entre janeiro de 1943 e janeiro de 1945, passando depois ao Diário de S. Paulo, onde manteve a seção "Notas de crítica literária", de setembro de 1945 a fevereiro de 1947. Candido já era livre-docente em Literatura Brasileira desde 1945, quando apresentou a tese sobre o método crítico de Sílvio Romero em concurso para a cadeira de Literatura Brasileira, antes de doutorar-se em Ciências Sociais (1954). Não deixa de ser inexato, portanto, dizer que ele passou da Sociologia para a Literatura.

${ }^{12} \mathrm{Cf}$. Antonio Candido. Memorial para concurso de professor titular, 1974 (fotocópia). Ver também o depoimento de Teresa Pires Vara. "Esboço de figurino". In: Flávio Aguiar (org.), Antonio Candido: pensamento e militância. São Paulo, Fundação Perseu Abramo, 1999. 
Faculdade de Assis o Segundo Congresso Brasileiro de Crítica e História Literária. Naquele congresso, Adolfo Casais Monteiro apresentara um relatório sobre "A crítica sociológica", tratando de Plekhanov e sobretudo Lukács. Discutindo o trabalho, Antonio Candido fez uma intervenção na qual formulava as ideias que depois seriam desenvolvidas em "Crítica e sociologia". ${ }^{13}$

No campo da crítica literária de intenção marxista, os principais nomes ainda eram Astrojildo Pereira e Nelson Werneck Sodré. Astrojildo, que por sinal participara do congresso em Assis com comunicação sobre Quincas Borba, tinha feito sua formação intelectual em período anterior, e seu estudo literário mais conhecido é o ensaio "Machado de Assis, romancista do Segundo Reinado" (1939). Não tendo desenvolvido uma concepção propriamente estética inspirada no marxismo, estudava as obras literárias valorizando-lhes o caráter documental, sem que o teor de conhecimento sedimentado na forma fosse reconhecido por ele. ${ }^{14}$ Enquanto as referências teóricas de Astrojildo (no campo da estética) não iam muito além de Plekhanov, Sodré é considerado o primeiro crítico brasileiro a citar extensamente as ideias de Lukács, na terceira edição de sua História da literatura brasileira, publicada em 1960. ${ }^{15}$ Não obstante as declarações de princípio apoiadas em Lukács, as quais sinalizam o desejo de ultrapassar o marxismo vulgar, o trabalho de Sodré permanece limitado ao estudo paralelístico ou ao ângulo externo da sociologia da literatura, tanto na História quanto no livro sobre O Naturalismo no Brasil, editado em 1965.

O período pré-1964 foi, como se sabe, de acirramento da luta popular e intensa politização das artes, dinamizada pelas transfusões de experiência social, no contato de intelectuais e estudantes com camponeses e operários. Aquele movimento representava uma aliança de classes nova, que possibilitou certa descompartimentação no plano da cultura, mas que no plano político tinha limitações, como o golpe de 1964 iria mostrar. Era o tempo do Movimento de Cultura Popular, das peças de agitprop dos CPCs, de filmes como Vidas secas, Deus e o diabo na terra do sol e Os fuzis, dos poemas engajados dos volumes Violão de rua

${ }^{13}$ Os Anais do congresso foram publicados em 1963, mas o registro dos debates é precário. Ver Anais do Segundo Congresso Brasileiro de Crítica e História Literária, 24-30 de julho de 1961. Assis, SP, Faculdade de Filosofia, Ciências e Letras, 1963. pp. 120-121. Ver também Antonio Candido. Entrevista (à revista Trans/form/ação), p. 233.

${ }^{14}$ Cf. Leandro Konder. "Astrojildo Pereira: o homem, o militante, o crítico". Memória E História, Revista do Arquivo Histórico do Movimento Operário Brasileiro. São Paulo, Liv. Ciências Humanas, 1981, n. 1, pp. 63-64. Para uma apreciação mais generosa dos estudos literários de Astrojildo, ver Martin Cezar Feijó. O revolucionário cordial: Astrojildo Pereira e as origens de uma política cultural. São Paulo, Boitempo, 2001.

${ }^{15}$ História da literatura brasileira: seus fundamentos econômicos. $3^{\mathrm{a}}$ ed. integralmente refundida. Rio de Janeiro, José Olympio, 1960. Para o quadro teórico de Sodré, ver a antologia Fundamentos da estética marxista. Rio de Janeiro, Civilização Brasileira, 1968. Sobre sua obra, ver Jorge Grespan. "O marxismo de Nelson Werneck Sodré". In: Marcos Silva (org.). Nelson Werneck Sodré na Historiografia brasileira. Bauru, Edusc, São Paulo, Fapesp, 2001, pp. 93-105. Sobre a recepção da obra de Lukács no Brasil, ver Celso Frederico. "A presença de Lukács na política cultural do PCB e na universidade". In: João Quartim de Moraes (org.). História do marxismo no Brasil. vol. II: Os influxos teóricos. Campinas, Ed. Unicamp, 2005, pp. 183-221. 
- e mesmo os concretistas, empurrados pela radicalização dos anos anteriores, acabariam por anunciar seu "salto participante", aliás naquele mesmo congresso de Assis em que Antonio Candido formulava sua plataforma crítica. ${ }^{16}$ Além disso, na luta pelas reformas de base alinhavam-se o PCB, a Ação Popular, os católicos de esquerda do semanário Brasil, Urgente e os isebianos, que naquele momento redigiram vários números dos Cadernos do povo brasileiro, com o intuito de "conscientizar" o povo. ${ }^{17}$

Em consonância com o ânimo daqueles anos, em que, nas palavras de Schwarz, "o país estava irreconhecivelmente inteligente", eram alguns críticos jovens que tentariam impulsionar a crítica dialética e a discussão da arte, inspirando-se no marxismo. No mesmo ano de 1965 em que Antonio Candido publicava Literatura e sociedade, saíram A sereia e o desconfiado, de Roberto Schwarz; Razão do poema, de José Guilherme Merquior; e a segunda edição (a primeira fora destruída pelos militares) de Cultura posta em questão, de Ferreira Gullar. Pouco depois, em 1967, apareciam Literatura e humanismo, de Carlos Nelson Coutinho; e Os marxistas e a arte, de Leandro Konder. ${ }^{18}$

Esse quadro esquemático talvez ajude a compreender por que, ao alertar que a dialética de forma literária e processo social é uma palavra de ordem fácil de lançar e difícil de cumprir, Roberto Schwarz assinala que "a sua difusão antes de 1964 era grande, sem que o resultado crítico fosse expressivo". Somente em 1970, com a publicação do ensaio de Antonio Candido sobre as Memórias de um sargento de milícias, a dialética "deixava de ser uma palavra vã", ${ }^{19}$ e isso apesar dos esforços daqueles críticos jovens - dos quais, acrescentemos, apenas Schwarz desenvolveria, sobretudo em seus estudos machadianos, a perspectiva aberta por Candido para a crítica literária. ${ }^{20}$

Em Literatura e sociedade Antonio Candido também passa por questões investigadas na Formação da literatura brasileira, indicando sua abrangência. Para além das menções pontuais à noção de sistema literário nos ensaios "O escritor e o

\footnotetext{
${ }^{16}$ Ver Décio Pignatari. "A situação atual da poesia no Brasil". In: Anais do Segundo Congresso Brasileiro de Crítica e História Literária, p. 388.

${ }^{17}$ Uma seleção de textos do período encontra-se em Arte em Revista, ano I, n. 1, janeiro-março 1979. Ver Roberto Schwarz. "Cultura e política, 1964-69", in: O pai de família e outros estudos. Rio de Janeiro, Paz e Terra, 1978. pp. 61-92; Seqüências brasileiras, pp. 119-20, 174. Daniel Pécaut. Os intelectuais e a política no Brasil: entre o povo e a nação. Trad. Maria Júlia Goldwasser. São Paulo, Ática, 1990, pp. 97-178.

${ }^{18}$ Curiosamente, Konder escreveu as orelhas de todos os quatro livros anteriores e em três delas busca promover a crítica de inspiração lukácsiana.

${ }^{19}$ Roberto Schwarz. "Pressupostos...", pp. 129 e 154. Inútil lembrar que é a esse problema - o da declaração de princípios que não corresponde à prática efetiva na análise das obras - que Candido se contrapõe ao dizer que seu propósito é "mostrar (não apenas enunciar teoricamente, como é hábito) de que maneira a narrativa se constitui a partir de materiais não literários, manipulados a fim de se tornarem aspectos de uma organização estética regida pelas suas próprias leis" (Prefácio a $O$ discurso e a cidade, p. 9)

${ }^{20}$ Não por acaso, foi Schwarz quem mostrou detalhadamente a força reveladora dos ensaios de Antonio Candido, nos estudos citados na nota 3. Ver também Paulo Arantes Sentimento da Dialética na experiência intelectual brasileira. Dialética e dualidade segundo Antonio Candido e Roberto Schwarz. Rio de Janeiro, Paz e Terra, 1992.
} 
público" e "Letras e ideias no período colonial", cumpre mencionar "Literatura e cultura de 1900 a 1945", que fornece elementos para a compreensão mais ampla da lógica da formação. Como se há de recordar, ao historiar o processo formativo da literatura brasileira em seus momentos decisivos, Candido reconstituiu o projeto da classe dominante, ligado ao esforço de atualização cultural, que buscava realizar seu desejo de construir aqui uma literatura, dotando o país recémindependente de mais um melhoramento civilizatório - e para isso acompanhou o ângulo dos românticos, sem, no entanto, aderir ao seu ponto de vista.

Um resultado fundamental do processo formativo é o surgimento de uma linha definida da tradição - resultado conquistado com dificuldades, devido à tensão entre localismo e cosmopolitismo que rege a dinâmica da vida cultural brasileira, fazendo-a alternar entre um polo e outro, o que estorvava a definição de linhas de continuidade no país. Como não é difícil notar, a tensão entre a realidade local e os moldes herdados da cultura europeia é um dado incontornável do período de formação da literatura nacional, manifestando-se, por exemplo, na "dupla fidelidade" dos escritores românticos, nos inícios do romance brasileiro, voltados para o empenho de registrar e pesquisar a realidade local e, simultaneamente, para a adesão às modas e aos padrões prestigiosos vindos dos países centrais. $^{21}$

Dando lugar ao estabelecimento de uma tradição, o sistema literário formado define ciclos de acumulação literária, lastreados pela continuidade da produção local. Os dois momentos decisivos em que isso ocorre, mudando os rumos e vitalizando a inteligência, são o Romantismo no século XIX e o Modernismo no século XX, períodos em que os pólos do localismo e do cosmopolitismo encontrariam certo equilíbrio. Esses momentos de equilíbrio são também etapas de acumulação e adensamento da experiência, que parecem possibilitar saltos qualitativos. Com efeito, verifica-se, na esteira daqueles momentos, os saltos dados por Machado de Assis, que "se embebeu meticulosamente da obra dos predecessores", 22 e pelos escritores que se beneficiaram da ruptura modernista, como Drummond e Graciliano Ramos, ainda nos anos 1930, ou João Cabral e Guimarães Rosa nos decênios seguintes.

As fases de acumulação assim definidas pelo sistema formado criam condições de possibilidade para o salto qualitativo, mas não garantem sua realização: no século XIX, por exemplo, simplesmente não ocorreu o salto no campo da poesia (a despeito da sociabilidade dos grupos de estudantes, que proporcionava o intercâmbio literário, mas que acabou integrando-se à comunidade, sem chegar a uma ruptura, como lembra Candido em "A literatura na evolução de uma

${ }^{21}$ Formação, vol. 2, pp. 97-105. Na formulação de Paulo Arantes, a mola secreta da dupla fidelidade da elite brasileira era "a coexistência e determinação recíproca do Centro e da Periferia no mesmo espaço social". ("A fratura brasileira do mundo" In: Zero à esquerda. São Paulo, Conrad, 2004, p. 57.)

${ }^{22}$ Formação, vol. 2, p. 104. Ver também Roberto Schwarz. "Acumulação literária e nação periférica", in: Um mestre na periferia do capitalismo. São Paulo, Duas Cidades, 1990, pp. 207-27. Paulo Arantes. "Providências...", p. 51. 
comunidade"). Assim também, ao tratar da literatura posterior a 1950, Candido assinala a "consolidação da média", com uma produção mais regular e de melhor qualidade do que em períodos anteriores, embora marcada por poucas "erupções de elevada criatividade". "Isso ocorre sobretudo a partir do momento no qual o crítico identificava (em "Literatura e cultura de 1900 a 1945") o surgimento de "padrões literários mais puros", como efeito da crescente especialização e divisão do trabalho intelectual, depois de um longo ciclo em que a literatura havia ocupado posição central na vida cultural brasileira. Com a delimitação de seu campo específico, a literatura se tornava mais "literária" (por assim dizer), mas ao mesmo tempo retraía o âmbito de sua ambição, atenuando a pesquisa de problemas sociais e históricos. É o que ocorria na chamada "Geração de 45" e, de modo mais acentuado, na neovanguarda posterior, em que se assumiam "linguagens mais ou menos desligadas do projeto nacional". ${ }^{24}$ (Quem olhasse por esse prisma o panorama dos últimos anos talvez encontrasse certa regularidade da média e ausência de obras mais fortes, e quem sabe arriscaria dizer que não só não tem havido saltos, como também a própria acumulação teria se tornado mais difícil, como se vivêssemos um novo período de "rarefação na densidade espiritual"25 - restando, é claro, explicar por quê.)

Repassando a linha formativa da experiência intelectual brasileira, adensada na literatura, Paulo Arantes esclarece que não se trata apenas de um conjunto de recursos expressivos disponibilizados pela tradição, mas de "um repertório historicamente ordenado de formas segundo as quais sondar a lógica singular da experiência brasileira e, por comparação, amadurecida a hora certa, a outra cena, mundial, de que somos parte"26. Essa sondagem foi amplamente desenvolvida na obra crítica de Roberto Schwarz, e seu viés comparativo - possibilitado pelo ângulo próprio da literatura, mas que coloca em confronto âmbitos inteiros do cenário mundial (assimétricos mas articulados) - talvez seja o desdobramento mais significativo da famosa observação de Antonio Candido segundo a qual "estudar literatura brasileira é, em boa parte, estudar literatura comparada"27.

Atentar para o enfoque comparativo, que já estava implicado na Formação e ganhou contundência no ensaio sobre $O$ cortiço, possibilita ainda notar um dos resultados teóricos da obra crítica de Antonio Candido, que faz entrever o alcance geral da realidade brasileira, em certo sentido diminuída, mas nem por isso irrelevante, pois, uma vez reconstruído o processo social correspondente à confi-

\footnotetext{
23 "A nova narrativa”. In: A educação pela noite e outros ensaios. São Paulo, Ática, 1987, p. 205.

24 "Literatura, espelho da América?". Remate de Males, número especial Antonio Candido, Campinas, 1999, p. 109.

${ }^{25}$ Formação, vol. 2, p. 101.

${ }^{26}$ Um departamento francês de ultramar: estudo sobre a formação da cultura filosófica uspiana. (Uma experiência nos anos 60). Rio de Janeiro, Paz e Terra, 1994, p. 172.

27 "O nosso romance antes de 1920 (I)" [1946], Literatura e sociedade, n. 5, São Paulo. DTLLC-FFLCH-USP, 2000, p. 213. No contexto original, a frase surge a propósito da falta de uma tradição local, sendo seguida de citação de Sílvio Romero, depois retomada por Paulo Arantes. "Providências...", p. 15.
} 
guração literária, revela-se o que a experiência brasileira tem a dizer sobre o curso do mundo, de que é parte. ${ }^{28}$

Para isso contribuiu um resultado prévio do processo formativo: depois de adaptados e ajustados, os padrões culturais impostos passaram também a figurar as contradições da ordem social, podendo assim funcionar como fermento crítico. ${ }^{29} \mathrm{Na}$ expressão de Candido, referente a outro momento histórico, era o surgimento imprevisto de uma "plantinha incômoda" ao lado da cultura que se queria transplantar e que gerava em seu flanco a própria contestação. ${ }^{30}$ Algo semelhante, aliás, já se insinua na ambiguidade atuante na estruturação d'O Caramuru, poema que pretendia ser exaltação do triunfo da empresa colonial portuguesa, mas que possibilitou também a afirmação do particularismo localista dos românticos, como mostrou Antonio Candido no notável ensaio "Estrutura literária e função histórica", sobre a recepção do poema de Durão. ${ }^{31}$ Um passo mais e o particularismo deixaria de ser apenas o pitoresco nativista, passando a incluir as contradições próprias da sociedade brasileira, como ocorreria nas Memórias de um sargento de milícias, objeto seguinte do crítico.

Isso posto, caberia lembrar que também havia limites na investigação histórica do modo como o projeto cultural da elite oitocentista havia se completado. Como observou Paulo Arantes em O fio da meada, as camadas subalternas estavam ausentes da reconstituição do processo formativo, ou seja, para além de menções pontuais à camada popular representada nas obras, não se encontra ali a perspectiva substantiva dos pobres. No entanto, estes fazem sua aparição efetiva, na literatura brasileira, justamente nos romances sobre os quais Antonio Candido escreveu seus ensaios fundamentais da década de 1970: "Dialética da malandragem" e "De cortiço a cortiço". A camada subalterna - o "outro" da elite pensante - está no centro daqueles romances e é agora o foco de atenção do crítico. O lugar dos pobres é então pensando em função das especificidades da organização social figurada nas obras, cuja lógica formal revelaria um dinamismo histórico que repõe relações brutais em seus movimentos de modernização.

Naqueles romances, o que se encontra configurado seria, assim, algo como o avesso da formação do sistema cultural, apresentando a semianomia dos que flutuam ao deus-dará entre a ordem e a desordem, nas Memórias de um sargento de milícias, ou os movimentos da exploração crua dos novos proprietários e seus efeitos devastadores entre os de baixo, n'O cortiço. Está ausente do panorama apresentado nas obras qualquer indício de integração efetiva ou de superação da inorganicidade social, apontando-se, desse modo, a precariedade da outra forma-

${ }^{28}$ Cf. Paulo Arantes. "Providências...", pp. 40-1.

${ }^{29}$ Cf. Paulo Arantes. "Providências...", pp. 54-55. A passagem retoma Antonio Candido. "Literatura de dois gumes". In: A educação pela noite, pp. 163-180.

30 "Feitos da burguesia". In: Teresina etc. Rio de Janeiro, Paz e Terra, 1980, pp. 103-104.

${ }^{31} \mathrm{Em}$ outro estudo sobre $O$ Caramuru, Candido analisa as paradas em meio à movimentação do poema, isto é, os remansos em que o poeta imagina a "ordem ideal" no "universo perigoso da desordem". Cf. "Movimento e parada". In: Na sala de aula. $3^{a}$ ed. São Paulo, Ática, 1989, pp. 7-19. A observação é de Paulo Arantes. Sentimento da dialética, p. 45. 
ção, que não se completara: a de uma nação relativamente coesa, a que, de um modo ou de outro, a formação do sistema literário estava atrelada. ${ }^{32}$

A formação da nação mais ou menos integrada, à maneira dos países centrais, havia pautado as interpretações do Brasil, que a projetavam para um momento futuro, sempre adiado. No entanto, a própria ilusão de integração futura se desfez, e hoje sabemos que aquela formação se "completou" em outro sentido, justamente enquanto formação inviabilizada. Por sinal, a redefinição do processo econômico que rifou a perspectiva de construção nacional também favoreceu uma nova versão do "desrecalque localista" - expressão com que Antonio Candido, em "Literatura e cultura de 1900 a 1945", caracterizava um vezo do Modernismo brasileiro, em cuja junção de particularidades nacionais e procedimentos vanguardistas "as nossas deficiências, supostas ou reais, são reinterpretadas como superioridades". Mas para os modernistas essa inversão não deixava de associarse a um projeto nacional (impulsionado pela industrialização que começava), ao passo que agora o panorama se encontra modificado, e a revalorização culturalista de traços nacionais, incluindo a malandragem, pode ser entendida no quadro da mundialização do capital. Como notou Celso Furtado, à medida que o conceito de sistema econômico nacional vai perdendo poder explicativo, os países passam a ser identificados cada vez mais como áreas culturais; ao que Paulo Arantes, retomando o raciocínio, acrescenta: "a identificação pela cultura, na falta de um suporte material que lhe dê lastro social coletivo, torna-se uma operação fraudulenta de fabricação de uma imagem a mais a ser lançada no mercado". ${ }^{33}$

No meio tempo, os portadores históricos da malandragem haviam mudado de feição: não eram mais os desclassificados da ordem colonial, nem os que, à margem do progresso, seriam incorporados à esfera do trabalho na era da industrialização; em vez disso, com a desagregação do mundo do trabalho, foram transformados em sujeitos monetários sem dinheiro (Kurz), parte integrante da modernização consumada. No campo de cima, passaria a predominar uma ideia de atividade econômica que não mais implica a perspectiva de construção da sociedade nacional, como que ampliando "a margem de liberdade absurda e antissocial de que a classe dominante - pelo seu canal com o progresso do mundo externo - dispõe no país" (Schwarz). Nas novas condições, o divórcio entre economia e nação faz com que a cultura nacional já não articule nenhum projeto coletivo de vida material, convertendo-se em mero trunfo comercial. ${ }^{34}$

Com a desagregação, que passou a ser o destino de grande parte do mundo contemporâneo, também se dissolveu a miragem de uma construção nacional futura, revelando-se, entre outras coisas, a estreiteza do quadro em que se ti19, 53-58

${ }^{32}$ Cf. Paulo Arantes. "Providências...", pp. 11-14. Roberto Schwarz. Seqüências brasileiras, pp. 18-

${ }^{33}$ Otília Arantes e Paulo Arantes. "O sentido da formação hoje", Praga: estudos marxistas, n. 4, São Paulo, dezembro 1997, p. 99. Ver também Celso Furtado. Brasil: a construção interrompida. Rio de Janeiro, Paz e Terra, 1992, pp. 25-26.

${ }^{34}$ Cf. Paulo Arantes. "A fratura brasileira do mundo". In: Zero à esquerda. São Paulo, Conrad, 2004, pp. 66-73; Roberto Schwarz. Seqüências brasileiras. 
nham movido os antigos projetos superadores, do nacional-desenvolvimentismo ao marxismo industrializante. E, no entanto, apesar de tudo, era a referência nacional, implicando a "imaginação formadora das comunidades políticas", que permitia aquela "regulação silenciosa [...] a que chamamos pensamento". ${ }^{35} \mathrm{~A}$ experiência brasileira, transnacional desde o início, e cujas peculiaridades a obra de Antonio Candido nos ensinou a investigar, continua sendo um ponto de partida para a reflexão, agora em um quadro novo. E para voltar a pensar, seria útil recordar, ainda uma vez, a tradição dos oprimidos, na qual o que conta não é a imagem nacional agora comercializada, mas sim aquilo que foi interrompido e permanece irrealizado para os pobres: a emancipação.

${ }^{35}$ Paulo Arantes. "Nação e reflexão". In: Zero à esquerda, pp. 103 e 100; "Fim de jogo". In: Extinção. São Paulo, Boitempo, 2007, p. 219. 